Deception detection in repeated interviews: The effects of immediate type of questioning on the delayed accounts

Aleksandras Izotovas

\author{
Aldert Vrij \\ Lorraine Hope \\ Leif A. Strömwall \\ Pär Anders Granhag \\ Samantha Mann \\ Author Note
}

Aleksandras Izotovas, Aldert Vrij, Lorraine Hope and Samantha Mann, Department of Psychology, University of Portsmouth; Leif Strömwall and Pär Anders Granhag, Department of Psychology, University of Gothenburg.

This work is part-funded by the High-Value Detainee Interrogation Group, DJF-151299-V-0010271 awarded to the University of Portsmouth (UK). Any opinions, findings, conclusions, or recommendations expressed in this article are those of the authors and do not necessarily reflect the views of the U.S. Government.

This research is part-funded by a fellowship awarded from the Erasmus Mundus Joint Doctorate Program The House of Legal Psychology (EMJD-LP) with Framework Partnership Agreement (FPA) 2013-0036 and Specific Grant Agreement (SGA) 2015-1610 to Aleksandras Izotovas. 
The authors would like to thank the Lithuanian Criminal Police Bureau's Training Centre for permission to use the stimulus video in this study. The authors are also thankful to the research assistants Christina van der Tuin-Rindestig and Jeanira Molina for their help.

Correspondence concerning this article should be addressed to Aleksandras Izotovas, Department of Psychology, University of Portsmouth, King Henry Building, King Henry 1 Street, PO1 2DY, Hants, United Kingdom. Email: alex.izotovas@port.ac.uk 


\begin{abstract}
In criminal investigation settings, the proper use of interviewing techniques is important to gather relevant and reliable information, and to effectively infer the credibility of an interviewee's account. In this study, we examined how different types of interviewing (eliciting more complete vs. less complete accounts) used in an interview conducted shortly after an event affected truth tellers' and liars' responses when they were interviewed again after a two-week delay. Participants $(n=80)$ were shown a mock intelligence operation video and instructed either to tell the truth or lie about its contents in two interviews, one of which took place immediately after watching the video and the other after a two-week delay. In the immediate interview participants were instructed either to report everything they remembered, or asked spatial questions related to the event. In the delayed interview, all participants were asked to report everything they could remember. Truth tellers reported more visual, spatial, temporal and action details than liars, both immediately and after a delay in both interviewing groups. However, the differences between truth tellers and liars were slightly larger in the report everything than in the spatial questions condition. Results suggest that an immediate 'report everything' instruction can provide a buffer against truth-tellers' decline in reporting details after a delay, and effectively discriminate between truthful and deceptive accounts.
\end{abstract}

Keywords: Report everything, deception detection, repeated interviewing, delay. 


\section{Deception detection in repeated interviews: The effects of immediate type of questioning on the delayed accounts}

The goal of any successful police investigation is to obtain reliable evidence for court proceedings (Gabbert, Hope, Carter, Boon, \& Fisher, 2016; Milne \& Bull, 1999). The testimony of witnesses plays an important role in criminal investigations, and so information collected from them in interviews must be both accurate and relevant to the case (Walsh \& Oxburgh, 2008). Research has shown that the way in which a witness is questioned can affect the quality of his/her statement (Memon, Meissner, \& Fraser, 2010). Inappropriate questioning during the investigative interview may result in memory distortions or incomplete or erroneous reports from interviewees, which may significantly deteriorate an investigation (Oxburgh, Myklebust \& Grant, 2010); moreover, it can impair possibilities to detect deception (Vrij \& Granhag, 2012).

In the legal system interviewees tend to be interviewed multiple times about the target event, often after long delay periods (Pansky, Koriat, \& Goldsmith, 2005; Wysman, Scoboria, Gawrylowicz, \& Memon, 2014). In the current research, we examined how the initial type of questioning affects the content and credibility of the subsequent delayed accounts.

\section{The role of initial immediate interviewing on subsequent delayed accounts}

Memory research has examined the effects of a time delay on the retrieval of information. Ebbinghaus (1885/1913) found that learned information tend to be lost over time when there are no attempts to retain it, a phenomenon described by the 'forgetting curve'. When the information has not been 'used' (retrieved), memory traces weaken (Pansky et al., 2005).

However, engaging in a high-quality initial recall attempt can be a protective factor to prevent memory decay (Hope, Gabbert, Fisher, \& Jamieson, 2014; Pansky \& Nemets, 2012). Memory theory suggests that an immediate, high-quality, recall enhances subsequent recall 
attempts from episodic memory because it strengthens activation levels of items and the associations between them (Anderson, 1983).

The interview techniques used in an initial interview affects the completeness and accuracy of the interviewee's recall. Specifically, proper interviewing can help to elicit more information and produce less errors from the interviewee. Previous studies found that interview formats that elicit high-quality (i.e. complete and accurate) initial accounts enhanced the amount and accuracy of reported information after a delay (Gabbert, Hope, \& Fisher, 2009; Hope et al., 2014).

In contrast, interview techniques eliciting incomplete initial recall attempts can impair later recall. One possible explanation for this is reduced accessibility to information that was not recalled initially (Hope et al., 2014; Levy \& Anderson, 2002). Thus, if initial accounts are not as complete as possible, there is a risk of substantial information loss at later reporting occasions (Macleod, 2002). That is, the details that were not the subject of retrieval practice during the initial interview may be poorly recalled in a subsequent interview(s), resulting in an impairment in memory quantity for what might be important information for a case (Shaw, Bjork, \& Handal, 1995). In the present study we compared two initial interviewing types. An instruction to report everything, an interview style advocated as 'good interviewing' in the interviewing literature (Achieving best evidence in criminal proceedings, 2011; Meissner, Surmon-Böhr, Oleszkiewicz, \& Alison, 2017), or an interview style that focused on specific questioning.

\section{Delay and deception detection}

Incomplete accounts can also affect credibility. First, deception research has shown that richness of detail in a statement is one of the most diagnostic cues to credibility, with truthful statements typically containing more details than deceptive ones (DePaulo et al., 2003; Vrij, 2008). Second, interviewers often associate lack of detail with poor credibility 
(Bogaard, Meijer, Vrij, \& Merckelbach, 2016; Strömwall \& Granhag, 2003). Although the role of type of questioning on human memory has been extensively researched (Memon et al., 2010), it is yet unknown how it affects discrimination between truth tellers and liars in a repeated interviewing (immediately and after a delay) context.

Deception detection research have shown that truthful and deceptive reports may vary in terms of amount of detail because of different strategies used by suspects during an interview (Hartwig, Granhag, \& Strömwall, 2007; Vredeveldt, van Koppen, \& Granhag, 2014). Truth tellers tend to be forthcoming, although the amount of information they provide depends on the interview style. If they are encouraged to provide all information they can remember they will report more details than when specific questions are asked that do not capture the entire experienced event (Vrij, Hope, \& Fisher, 2014). Liars face an informationmanagement dilemma (Granhag \& Hartwig, 2008). Feigning memory loss or providing only 'I don't know' answers will not give leads to investigators, but may hamper credibility because they result in statements that lack detail. Therefore, liars need to provide details to make a convincing impression, but, at the same time, need to withhold from reporting certain information (typically, incriminating information) to avoid the risk of getting caught. To achieve this, they often prepare themselves for possible interviews and think about what they may say in the interview (Granhag \& Hartwig, 2008). They may therefore be less sensitive to the type of question that is asked than truth tellers.

A delay can negatively affect deception detection because of genuine forgetting experienced by truth tellers. Recent research has shown that participants tasked with lying may experience difficulties in understanding the real nature of memory (Harvey, Vrij, Hope, Leal, \& Mann, 2017). That is, while truth tellers tend to report fewer details after a delay (Lawson \& London, 2015; Turtle \& Yuille, 1994), liars tend to show a 'stability bias', a metacognitive failure to correctly understand the degree to which memory declines over time 
(Harvey et al., 2017; Kornell \& Bjork, 2009). Since the passage of time can undermine discrimination between truth tellers and liars (Harvey et al., 2017), we were interested to examine whether immediate interviewing could assist in later distinguishing truthful from deceptive accounts after the delay. In addition, we compared the effectiveness of two types of immediate interviewing (complete and less complete) to detect deception in the delayed accounts.

In the current study we introduced two ways of immediate interview, i) report everything (promoting comprehensive retrieval) and ii) spatial open-ended questions (promoting selective retrieval); and examined how these questioning types affected the delayed reports of truth tellers and liars. The report everything instruction is a mnemonic technique that prompts interviewees to disclose all information they remember, whether it seems trivial or not (Fisher \& Geiselman, 2010). This technique is valuable because details that an interviewee considers to be irrelevant may be important for the investigation, and recall of some details may activate memories of other relevant details (Fisher \& Geiselman, 1992).

Regarding spatial open-ended questioning, spatial details are important because they give valuable knowledge about directions of movement, locations of people or objects, or the layout of crime scene (Hope, Gabbert, \& Fisher, 2011). However, when the interviewer puts emphasis only on questioning about one aspect of the event (spatial information), but neglects to ask questions about the other aspects (e.g., descriptions about actions of people during the crime), there is a risk to elicit less complete statements at the initial interview and after a delay (Gabbert et al., 2016).

We speculated that the less complete initial interviewing (spatial questions) would produce fewer associative links, and, as a result, less detailed accounts than the complete interviewing (report everything instruction). Therefore, the difference between truth tellers 
and liars is likely to be reduced with the interview type eliciting less complete truthful accounts.

It was predicted that truth tellers would report more visual, spatial, temporal and action details than liars after a delay in the comprehensive (report everything) retrieval condition (Hypothesis 1). Compared to liars, truth tellers would report more visual and spatial details and an equal amount of temporal and action details in the delayed statements of the selective (spatial questions) retrieval condition (Hypothesis 2). The first two hypotheses were derived from the notion that truth tellers and liars should perceive the interview questions/instructions in different ways. As truth tellers tend to use forthcoming strategies to report information during the interview (Hartwig et al., 2007), their reports should contain the types of detail that the specific instruction is expected to elicit. The report everything instruction encourages complete answers from interviewees. Therefore, it is expected to obtain from truth teller reports with a wide range of details, such as visual, spatial, temporal, and action details. Spatial questions in the selective retrieval condition are specific and less likely to include details which are not space-related such as temporal and action details. Space-related information should contain visual and spatial details because they are meaningfully related. That is, descriptions of locations and spatial arrangements (i.e., spatial details) typically include descriptions of objects and/or people (i.e., visual details).

Given liars' efforts to think in advance about what they would like to say (Nahari et al., 2014), and their difficulties in understanding the real nature of memory (Harvey et al., 2017), they should be less affected than truth tellers by the specific nature of the question. Therefore, truth tellers and liars should differ only in terms of number of reported visual and spatial details in the selective retrieval condition.

Following Hypotheses 1 and 2 that imply truth tellers should benefit more from the report everything instruction than from the spatial questions, we expected an interaction: 
differences between truth and liars to be larger in the comprehensive than the selective retrieval condition in the delayed statements (Hypothesis 3).

\section{Method}

\section{Participants}

A total of 80 volunteers took part in the study. The mean age of participants was $M=$ $31.81(S D=10.12)$ and $72.8 \%$ were female and $27.2 \%$ were male. Participants were recruited via posters, flyers, and a volunteer database. Fluent English speakers were required to take part in the study because verbal content of the statement was examined. The majority of participants were not English native speakers, therefore, they were asked to rate their fluency in language before the beginning of the experiment ${ }^{\mathrm{i}}$. They were awarded with shopping vouchers worth 100 SEK (approx. €10) after they completed the experiment. In addition, all participants were entered into a draw to win a single prize worth $1000 \mathrm{SEK}$.

\section{Design}

A 2 (Veracity: Truthful vs Deceptive) $\times 2$ (Initial Retrieval: Comprehensive vs selective $) \times 2$ (Time of Interview: Immediate vs delayed) experimental design was used with Veracity and Initial Retrieval as between-subject factors and Time of Interview as withinsubjects factor. Visual, spatial, temporal, and action details were the dependent variables for the types of detail analysis. Participants were randomly assigned to the Veracity and Retrieval conditions (comprehensive retrieval: truth tellers, $n=18$; liars, $n=20$; selective retrieval: truth tellers, $n=22$; liars, $n=20$ ). All participants were interviewed twice, immediately after the stimulus event and two weeks later. Not all participants were available exactly 14 days after the first interview, therefore, the delay time for the second interview varied between 8 ( $n$ $=3)$ and $27(n=1)$ days $(M=14.66, S D=3.67)$. The delay time for majority of participants $(45 \%)$ was 14 days. Truth tellers $(M=14.55, S D=3.00)$ and liars $(M=14.78, S D=4.27)$ 
did not differ with respect to the delay between the immediate and delayed interviews, $t(78)=$ $0.27, p=.786, d=0.06$. In addition, Pearson's correlations between the delay time and the total amount of details reported in the delayed interview were not significant for truth tellers, $r=0.11, p=.507$, and liars, $r=-0.13, p=.938$. These results show that heterogeneity of delay time of interviewing participants did not affect the differences between truth tellers and liars in the amount of details reported.

\section{Materials}

Stimulus event. A video depicting a simulated break-in was used in the current study. The video lasts five minutes. It shows a man entering a room in a basement floor through a corridor, taking some items (mobile phones, jewellery, a laptop, etc.) from the room, and then leaving the place.

\section{Procedure}

Pre-interview phase. Participants were instructed to consider that they were in the video described above, and they were following the other person in that video. They were also given the instruction to take the role of intelligence officer working undercover with another officer who was seen in the video. They were told their task was to break into an apartment with that officer and secure important information for intelligence gathering. All participants were instructed that the apartment they broke into was a staff room of a community centre. This special task was recorded from the perspective of the person who followed the other man throughout the break-in. Therefore, the participants were instructed 'to follow' the intelligence officer seen in the recording.

After watching the break-in video, participants were randomly assigned to the veracity conditions. Truth tellers were informed that the break-in was successful and they would be interviewed by a fellow agent to continue the investigation. They were asked to tell the truth during the interview about 1) the interior of the staff room in the video, and 2) what 
they took from there. Liars were also informed that the break-in was successful. However, they were instructed that they would be interviewed by an agent of a hostile agency and that their task was to create a convincing cover story. If the hostile officer came to know about the exact place they broke into and what was taken from there, the entire investigation would be in danger. Therefore, liars were instructed to fabricate details about 1) the interior of the staff room in the video, and 2) what they took from there.

To increase participants' motivation to be convincing in the interviews, they were told that if they were convincing during the interviews, they would receive a full 100 SEK reward and entered in the draw to win 1000 SEK worth prize. If they were not convincing enough, i.e. the interviewer thought they did not report everything they remembered, they were told that they would only receive $50 \mathrm{SEK}$, would be excluded from the draw, and would have to write a full statement of what happened in the video.

After the veracity instructions, participants were offered unlimited time to prepare for the interview. After preparation, a pre-interview questionnaire was administered. Participants were requested to respond truthfully. In the questionnaire participants were asked to rate on 7-point scales their preparation for the interview. They were asked to indicate how well they were prepared $(1=$ very poor, $7=$ very good $)$; and how sufficient $(1=$ insufficient, $7=$ sufficient $)$ and complete $(1=$ incomplete, $7=$ complete $)$ their preparation was. These three preparation items were clustered into one variable, Preparation quality (Cronbach's alpha was .95 for the immediate and .90 for the delayed interviews). The pre-interview questionnaire also included questions about their levels of stress and motivation, and subjective confidence in being convincing in the upcoming interview. These answers were also rated on 7-point scales $(1=$ not at all, $7=$ totally $)$.

Interviews. The participants were questioned by an interviewer who was blind to the aims of the study, stimulus material, and veracity conditions. 
In the immediate interview of the Comprehensive retrieval condition, truth tellers and liars were asked to provide a free recall, i.e. to report everything they could remember from the break-in, including descriptions of objects and locations, the sequences of actions, and information about any people that were involved. They were also asked to not guess about details that they could not remember.

In the immediate interview of the Selective retrieval condition, truth tellers and liars were not invited to give a free recall, but were asked five open-ended questions related to spatial characteristics of the break-in instead. The questions asked by the interviewer were: i) Describe the corridor of the apartment you broke into; ii) Describe the interior of the staff room; iii) Describe distinguishing features of the staff room; iv) Describe the outside area of the building you entered into; and v) Which items were taken and describe where they were taken from?

After the immediate interview, the first session of the experiment was completed. All participants were told that the second part of the experiment would be after two weeks. When participants returned for the second interview, interviewees in all conditions were asked to provide a free recall, report everything.

Post-interview phase. Participants completed a post-interview questionnaire after the delayed interview only. As with the pre-interview questionnaire, truth tellers and liars were requested to be honest with their responses. The post-interview questionnaire included questions about what they thought the likelihood was of i) receiving the $100 \mathrm{SEK}$, and ii) having to write a statement $(1=$ not at all, $7=$ very likely $)$. We also asked participants about the extent to which they i) told the truth, and ii) lied during the interview. Participants indicated on 11-point Likert scales ranging from $0 \%$ (not at all) to $100 \%$ (totally). These two questions were asked on both occasions to assess the truthfulness in both the immediate and delayed accounts. 
After completing the post-interview questionnaire, all participants were thanked, fully debriefed, and rewarded with a shopping voucher worth 100 SEK for participation in the experiment. After full data collection, one participant was randomly selected as the lottery winner.

\section{Coding}

Interviews were audio recorded and then transcribed verbatim. All statements were coded for the details provided in both the immediate and delayed accounts. Each detail was counted once per interview. Four types of detail were coded: i) visual details: specific items/descriptions of items reported by interviewee. For example, "my colleague ${ }^{1}$ was

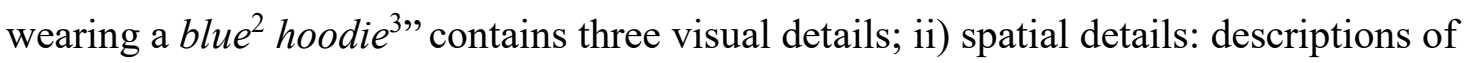
locations or spatial arrangements of people or objects. For example, "we went a few steps down ${ }^{1}$ and turned left ${ }^{2}$ " has two spatial details; iii) temporal details: information about the sequence of activities, their duration, or mentioning when something happened. For example, "When ${ }^{1}$ I entered the corridor, a neighbour looked at me for a few seconds ${ }^{2}$ " contains two temporal details; and iv) action details: information about the actions/activities in the event. For example, "He searched ${ }^{1}$ a coat, found ${ }^{2}$ a mobile phone, and $p u t^{3}$ it in his pocket" has three action details. A similar coding system has been used in previous studies (e.g., Warmelink, Vrij, Mann, \& Granhag, 2013).

The first coder, the first author of this study, coded all transcripts. The second coder, blind to the hypotheses, stimulus event, and veracity of the statements, coded a random sample of $16(20.0 \%)$ interview scripts to assess reliability. Inter-rater reliabilities between the two coders for the frequency of detail in both (immediate and delayed) statements were measured via intraclass correlation coefficients (ICC). The ICC revealed excellent inter-rater values: .95, CI [.22,.99] for visual details; .96, CI [.76,.99] for spatial details; .97, CI [.85,.99] for temporal details; and .99, CI [.97,1.00] for action details. 


\section{Results}

\section{Manipulation checks}

Mixed ANOVAs with Veracity as the between-subjects factor and Time of Interview as the within-subject factor were used for all the manipulation checks. Mean scores, standard deviations and confidence intervals for truth tellers and liars are presented in Table 1.

Insert Table 1 about here

There was a main effect of Veracity condition on self-reported truthfulness. Truth tellers reported that they were more truthful than did the liars during both the immediate, $F(1$, $78)=257.82, p<.001, d=3.59$ and delayed interviews, $F(1,78)=350.77, p<.001, d=$ 4.19, indicating that participants complied with the instructions given. No significant Veracity main effects were found regarding the other manipulation measures, all $F^{\prime} s<2.81$, all $p$ 's $>.09$, see Table 1. However, importantly, the results showed that participants were motivated and rated their preparation quality as high. Lack of motivation and lack of preparation time are considered factors that have a detrimental effect on ecological validity (Vrij, 2008).

The Time of Interview main effect was significant for Preparation time, $F(1,73)=$ $11.73, p=.001, d=0.34$. Participants took longer to prepare before the immediate interview $(M=165.48, S D=148.07,95 \%$ CI $[132.72,199.32])$ than before the delayed interview $(M=$ 121.11, $S D=127.38,95 \%$ CI $[94.86,147.36])$. This makes sense because participants were less familiar with the settings before the immediate interview than before the delayed interview. The other Time of Interview main effects were not significant, all $F$ 's $<3.12$, all $p ’ s>.081$.

A significant Veracity $\times$ Time of Interview interaction effect emerged for Motivation, $F(1,74)=6.31, p=.014, \eta_{\mathrm{p}}^{2}=.08$. Truth tellers $(M=6.30, S D=0.94,95 \%$ CI $[5.93,6.67])$ expressed higher levels of motivation than liars $(M=5.72, S D=1.37,95 \% \mathrm{CI}[5.34,6.11])$ 
before the immediate interview, $t(74)=2.17, p=.033, d=0.49$. However, the means show that participants in both groups were highly motivated as their scores were at the upper end of the motivation scale. The motivation level of truth tellers and liars did not differ before the delayed interview, $t(74)=0.18, p=.861, d=0.04$. The Veracity $\times$ Time of Interview interaction effect was also significant for Preparation time, $F(1,73)=6.92, p=.010, \eta_{\mathrm{p}}^{2}=$ .09 . Liars $(M=201.54, S D=150.84,95 \%$ CI $[154.14,248.94])$ took longer than truth tellers to prepare before the immediate interview $(M=130.50, S D=138.40,95 \% \mathrm{CI}$ $[83.73,177.27]), t(73)=2.13, p=.037, d=0.49$, whereas the Preparation time for truth tellers and liars was similar before the delayed interview, $t(73)=0.04, p=.971, d=0.01$. Again, this may be due to liars being less familiar with the settings before the immediate interview than before the delayed interview. All other Veracity $\times$ Time of Interview interaction effects were not significant, all $F^{\prime} s<3.29, p$ 's $>.075$.

Finally, oneway ANOVAs with Veracity as the sole factor and (i) Times thought about the event/story before the second interview, (ii) Incentive (likelihood of getting 100 SEK), and iii) Likelihood to write a statement as dependent variables revealed no significant main effects for Veracity, $F{ }^{\prime} s<2.34, p$ 's $>.131$. In the three latter analyses Interview was not included as a factor as the questions referred to the two interviews combined. Again, although previous research showed differences between truth tellers and liars regarding these variables (Ewens et al., 2016; Vrij et al., 2009), we cannot think of a theoretical reason as to why the absence of a Veracity effect would be detrimental.

The effects of the immediate retrieval on the number of details in the delayed accounts (Hypothesis 1, 2, and 3)

To examine whether the number of reported details differed between truthful and deceptive statements in the delayed interview, a MANOVA with Veracity and Initial Retrieval as the between-subjects factors and visual, spatial, temporal, and action details as 
the dependent variables revealed a significant multivariate Veracity main effect, $F(4,73)=$ $25.82, p<.001, \eta_{\mathrm{p}}^{2}=.59$. Univariate Veracity main effects were significant for visual, $F(1$, $76)=55.66, p<.001, \eta_{\mathrm{p}}^{2}=.42$, spatial, $F(1,76)=53.14, p<.001, \eta_{\mathrm{p}}^{2}=.41$, temporal, $F(1$, $76)=69.05, p<.001, \eta_{\mathrm{p}}^{2}=.48$, and action details, $F(1,76)=90.09, p<.001, \eta_{\mathrm{p}}^{2}=.54$. There was also a significant multivariate Initial Retrieval main effect, $F(4,73)=6.73, p<$ $.001, \eta_{\mathrm{p}}^{2}=.27$. At a univariate level, the Initial Retrieval main effects were significant for spatial, $F(1,76)=11.67, p=.001, \eta_{\mathrm{p}}^{2}=.13$, temporal, $F(1,76)=9.79, p=.002, \eta_{\mathrm{p}}^{2}=.11$, and action details, $F(1,76)=24.66, p<.001, \eta_{\mathrm{p}}^{2}=.25$, but not significant for visual details, $F(1,76)=16.20, p=.059, \eta_{\mathrm{p}}^{2}=.05$

The multivariate Veracity $\times$ Initial Retrieval interaction effect was not significant, $F(4,73)=4.31, p=.222, \eta_{\mathrm{p}}^{2}=.07$. This interaction statistic refers to all kinds of interaction, not specifically to the ones we were interested in when testing Hypotheses 1 and 2 -whether there are significant differences between truth tellers and liars in reporting details within a specific group (e.g., comprehensive and selective retrieval conditions). To test Hypotheses 1 and 2, simple effects analyses are required, that is examining Veracity effects within the Comprehensive condition, and Veracity effects within Selective the retrieval condition separately. See also Nahari and Ben-Shakhar (2011); Shaw et al. (2015) and Vrij et al. (2017) for similar approaches.

Insert Table 2 about here

To examine the hypothesis concerning differences in reporting the number of details between truth tellers and liars across initial retrieval conditions in the delayed interviews, simple effects analyses were conducted. Table 2 shows that truth tellers reported significantly more visual, spatial, temporal, and action details than liars in the comprehensive initial retrieval condition after the delay. Hypothesis 1 was fully supported. Truth tellers also reported significantly more visual, spatial, temporal, and action details than liars in the 
selective initial retrieval condition after the delay. Hypothesis 2 was partially supported because it was predicted that truth tellers would only report more visual and spatial details than liars in the selective retrieval condition after the delay.

Although the multivariate Veracity $\times$ Initial Retrieval condition was not significant, at a univariate level, significant interactions emerged for visual, $F(4,76)=4.31, p=.041, \eta_{\mathrm{p}}^{2}=$ .05 , and action details, $F(4,76)=4.88, p=.030, \eta_{\mathrm{p}}^{2}=.06$. The interaction effects were not significant for spatial, $F(4,76)=3.14, p=.080, \eta_{\mathrm{p}}^{2}=.04$, and temporal details, $F(4,76)=$ $1.38, p=.244, \eta_{\mathrm{p}}^{2}=.02$. To avoid the risk of a Type II error, we felt that interpreting these two significant interaction effects is appropriate. A $p$-value provides information about the statistical relevance but not about the practical importance of an effect (Fritz, Morris, \& Richler, 2012; du Prel, Hommel, Röhrig, \& Blettner, 2009). In this article, we are interested in the practical relevance of the effect and $d$-values are indicators of practical relevance (Fritz et al., 2012).

In the comprehensive retrieval condition, the effect sizes were $1.96,95 \% \mathrm{CI}$ [1.18,2.73] for visual, and $2.16,95 \%$ CI $[1.35,2.95]$ for action details. In the selective retrieval condition, the effect sizes were $1.30,95 \% \mathrm{CI}[0.61,2.93]$ for visual, and $2.09,95 \%$ CI $[1.30,2.79])$ for action details. Although the effect sizes were large in both retrieval conditions, they were somewhat lower for visual details in the selective than in the comprehensive retrieval condition. Hypothesis 3 was supported for visual details but rejected for spatial, temporal, and action details. Hypothesis 3 was thus partially supported.

\section{Exploratory analysis of the number of details in the immediate accounts}

Although the hypotheses were focused only on the delayed accounts, we also considered it important to examine the effect of the two interview techniques on the immediate statements made by truth tellers and liars. A MANOVA with Veracity and Initial Retrieval as the between-subjects factors and visual, spatial, temporal, and action details as 
the dependent variables revealed a significant multivariate effect for Veracity, $F(4,73)=$ $15.08, p<.001, \eta_{\mathrm{p}}^{2}=.45$. Univariate Veracity main effects were significant for visual, $F(1$, $76)=30.20, p<.001, \eta_{\mathrm{p}}^{2}=.28$, spatial, $F(1,76)=32.85, p<.001, \eta_{\mathrm{p}}^{2}=.30$, temporal, $F(1$, $76)=54.60, p<.001, \eta_{\mathrm{p}}^{2}=.42$, and action details, $F(1,76)=50.88, p<.001, \eta_{\mathrm{p}}^{2}=.40$.

There was a significant multivariate Initial Retrieval effect, $F(4,73)=23.64, p<.001, \eta_{\mathrm{p}}^{2}=$ .56. At a univariate level, the Initial Retrieval main effects were significant for spatial, $F(4$, $76)=17.13, p<.001, \eta_{\mathrm{p}}^{2}=.18$, temporal, $F(4,76)=39.14, p<.001, \eta_{\mathrm{p}}^{2}=.34$, and action details, $F(4,76)=51.11, p<.001, \eta_{\mathrm{p}}^{2}=.40$. The univariate Initial Retrieval main effect was not significant for visual details, $F(4,76)=0.34, p=.561, \eta_{\mathrm{p}}^{2}=.004$. A multivariate Veracity $\times$ Initial Retrieval interaction effect was also significant, $F(4,73)=5.74, p<.001, \eta_{\mathrm{p}}^{2}=.24$. At a univariate level, the interaction effects were significant for visual, $F(4,76)=4.44, p=$ $.038, \eta_{\mathrm{p}}^{2}=.06$, spatial, $F(4,76)=5.70, p=.019, \eta_{\mathrm{p}}^{2}=.07$, temporal, $F(4,76)=17.07, p<$ $.001, \eta_{\mathrm{p}}^{2}=.18$, and action details, $F(4,76)=18.63, p<.001, \eta_{\mathrm{p}}^{2}=.20$. The interaction effects are more informative than the two main effect components results. The immediate accounts results suggest that the effects were somewhat larger for visual, spatial, temporal, and action details in the comprehensive than in the selective retrieval condition, see Table 3.

\section{Discussion}

The current study examined the impact of an immediate retrieval attempt (report everything vs. spatial questions) on the delayed accounts of truth tellers and liars. As predicted, truth tellers reported more visual, spatial, temporal, and action details after the delay than liars, when asked to report everything they remembered in the initial interview (comprehensive retrieval). Since Harvey et al. (2017) found no difference between truth tellers and liars after a delay when interviewed only once, this finding suggests that truth tellers benefited from the initial memory enhancement. That is, an extensive immediate 
retrieval attempt (report everything) could increase activation levels of details during the delayed recall (Anderson, 1983). Thus, large amounts of visual, spatial, temporal, and action details could be accessible for truth tellers when they were interviewed after a delay. Liars reported fewer of these details than truth tellers because they had to manage the output of the amount of information (Granhag \& Hartwig, 2008). This is a common strategy used by liars because revealing too many details of the event increases the risk of providing investigators with new leads (Vrij, 2008).

Truth tellers also reported more visual, spatial, temporal, and action details than liars in the delayed accounts, when asked only spatial questions in the immediate interviews (selective retrieval). A possible explanation for this finding derives from activation theory of memory (Anderson, 1983). Specifically, truth tellers in the selective initial retrieval condition could concentrate on reporting visual and spatial details because of the nature of the questions in the immediate interview. As these details were associated with the other details in their episodic memory of the break-in, temporal and action details may have been easily accessible in the delayed interview. Therefore, the difference between truth tellers and liars was not only in reporting visual and spatial details, as predicted, but also in reporting temporal and action details, which was not predicted. Liars reported fewer visual, spatial, temporal, and action details than truth tellers in the selective retrieval condition, probably because of the different strategies they employed (Hartwig et al., 2007).

Although truth tellers differed from liars in both initial retrieval conditions in the delayed interview, it was expected that using the report everything instruction in the immediate interview would magnify these differences. Discrimination was indeed larger for reporting visual details in the comprehensive condition than in the selective retrieval condition. Truth tellers had a more extensive immediate retrieval attempt, when the report everything instruction was provided to them. As a result, visual details in the comprehensive 
initial retrieval could be more accessible in truth tellers' memories than visual details in selective initial retrieval, which resulted in larger differences between truth tellers and liars in the delayed interviews. This explanation becomes more compelling when considering the number of details reported by truth tellers and liars in the immediate accounts. Results in the exploratory analysis showed that the differences between truth tellers and liars were larger for visual, spatial, temporal, and action details in the comprehensive than in the selective retrieval condition.

Findings from the current study have important implications from an applied perspective. The results suggest that interviewing techniques eliciting complete accounts from interviewees at an early stage (e.g. report everything mnemonic) are promising in discriminating truth tellers from liars at later stages of the investigation. Thus, the current study shows that techniques promoting extensive free recall about the event in question are not only beneficial in terms of retrieval performance (Hope et al., 2014; Pescod, Wilcock, \& Milne, 2013), but also in detecting deception. A comparison of the $d$-values showed that a comprehensive initial retrieval produced somewhat larger differences between truth tellers and liars than a selective initial retrieval.

\section{Methodological considerations and future research}

This study had a few limitations. First, it involved a relatively small sample size. However, post hoc power analyses showed that this study had acceptable power (Cohen, 1992) of 0.93 or above for the obtained effect sizes that were statistically significant. Therefore, it can be concluded that the study was not underpowered for hypotheses testing.

Second, we did not include a control group, a condition in which participants would be interviewed only after a delay. The aim of the study was to compare the two questioning styles in the initial interview for which a control condition is not needed. In addition, previous studies have shown that truth tellers report more details than liars when the first 
interview has been conducted shortly after an event, whereas truth tellers and liars report a similar amount of detail when they were first interviewed after a delay (Harvey et al., 2017; Vrij et al., 2009). Thus, we cannot think of a theoretical reason as to why a "no immediate interview" control group would produce different findings from the current study. Nevertheless, the lack of s control condition makes it difficult to determine whether truth tellers reported more details in the delayed interviews than liars because of the immediate retrieval practice or because of the specific interviewing technique used. Future studies could include a control condition to address this issue.

Third, the sample contained non-native English speakers, who all could be considered fluent in English. In that respect this non-native sample differed from other deception research with non-native speakers in which participants are typically selected who are not fluent (Ewens et al., 2016). Research into the relationship between language proficiency and verbal deception is relevant but scarce. In case of poor language proficiency, the ability to verbally report stories could affect liars more than truth tellers because of increased cognitive load (Vrij, 2015). The issue of proficiency in language and its relationship to verbal lie detection should be examined in the future studies.

As noted, some manipulations were not successful (e.g. self-reported stress and confidence levels before the interviews were similar across veracity groups), whereas the cognitive approach to lie detection proposes that lying is more mentally demanding than telling the truth (Vrij, 2015). Differences between veracity groups were trending in the predicted direction (e.g., truth tellers' mean scores were lower for stress levels, and higher for confidence levels than liars' mean scores). However, there was lack of power ( 0.48 or below) (Cohen, 1992) to achieve significance for medium or low effect sizes (Cohen's $d$ 's for nonsignificant manipulation checks were 0.43 or below). Nevertheless, truth tellers and liars indicated high motivation levels and preparation quality before both interviews, which is a 
critical requirement to resemble real life settings (DePaulo et al., 2003). Deception detection research has shown that the responses of truth tellers and liars differ more from each other when participants are motivated (DePaulo et al., 2003). Research also shows that liars tend to prepare for their interviews (Hartwig, Granhag, \& Strömwall, 2007; Hartwig, Granhag, Strömwall, \& Doering, 2010) and that preparation makes liars to sound more similar to truth tellers (DePaulo et al., 2003). However, motivation and preparation are not the only factors affecting the elicitation of differences between truth-tellers and liars. For example, the questions asked in an interview also have an effect (Vrij, Fisher, \& Blank, 2017; Vrij \& Granhag, 2012). Inappropriate interviewing techniques tend to reduce/eliminate differences in truth tellers' and liars' responses and subsequently hamper deception detection. In this paper, we wanted to examine whether one type of questioning could be more effective in eliciting differences in truth tellers' and liars' responses than another type of questioning.

Regarding future directions, we examined the effect of initial interviewing styles when these interviews were carried out immediately after the event. Further deception detection studies could examine the effects of initial interviewing techniques on repeated statements when the first interview takes place after some delay, a scenario that is realistic for many criminal investigations.

\section{Conclusion}

The findings of our study showed that the way an immediate interview is conducted can play a role for credibility assessment in subsequent (delayed) interviewing. Because in the legal system the same individuals tend to be interviewed more than once, immediate, high-quality questioning can be helpful during subsequent interviews to discriminate between truthful and deceptive accounts. However, given a few limitations of the current experiment, the innovative nature of the experiment, and the moderate support for Hypothesis 3 , only 
modest conclusion can be made. We encourage researchers to continue the examination of the effects of early questioning on deception detection at later interviewing. 


\section{References}

Anderson, J. R. (1983). A spreading activation theory of memory. Journal of Verbal Learning and Verbal Behavior, 22, 261-295. DOI:10.1016/S0022-5371(83)90201-3

Bogaard, G., Meijer, E., Vrij, A., \& Merckelbach, H. (2016). Scientific content analysis (SCAN) cannot distinguish between truthful and fabricated accounts of negative events. Frontiers in Psychology, 7, 243. DOI: 10.3389/fpsyg.2016.00243

Cohen, J. (1992). A power primer. Psychological Bulletin, 112, 155-159. DOI: 10.1037/0033-2909.112.1.155

Du Prel, J-B., Hommel, G., Röhrig, B., \& Blettner, M. (2009). Confidence interval or pvalue? Deutzches Arzteblatt International, 106, 335-339.

Doi:10.3238/arztebl.2009.0335.

Ebbinghaus, H. (1885/1913). Memory: A contribution to experimental psychology. New York: Teachers College, Columbia University.

Ewens, S., Vrij, A., Leal, S., Mann, S., Jo, E., Shaboltas, A., Ivanova, M., Granskaya, J., \& Houston, K. (2016). Using the Model Statement to Elicit Information and Cues to Deceit from Native Speakers, Non-native Speakers and Those Talking Through an Interpreter. Applied Cognitive Psychology, 30, 854-862. DOI: 10.1002/acp.3270

Fisher, R., \& Geiselman, R. (1992). Memory-enhancing techniques for investigative interviewing: The cognitive interview. Springfield, IL: Thomas.

Fisher, R. P., \& Geiselman, R. E. (2010). The cognitive interview method of conducting police interviews: Eliciting extensive information and promoting therapeutic jurisprudence. International Journal of Law and Psychiatry, 33, 321-328. DOI: 10.1016/j.ijlp.2010.09.004 
Fritz, C. O., Morris, P. E., \& Richler, J. J. (2012). Effect size estimates: Current use, calculations and interpretation. Journal of Experimental Psychology: General, 141, 218, DOI: $10.1037 / \mathrm{a} 0024338$

Gabbert, F., Hope, L., Carter, E., Boon, R., \& Fisher, R. (2016). The role of initial accounts within the investigative process. In G. Oxburgh, T. Myklebust, T. Grant \& R. Milne (Eds.), Communication in Investigative and Legal Contexts (pp. 107-131). Chichester, UK: Wiley.

Gabbert, F., Hope, L., \& Fisher, R. P. (2009). Protecting eyewitness evidence: Examining the efficacy of a Self-Administered Interview tool. Law \& Human Behavior, 33, 298-307. DOI:10.1007/s10979-008-9146-8

Granhag, P.A. \& Hartwig, M. (2008). A new theoretical perspective on deception detection: On the psychology of instrumental mind-reading. Psychology, Crime \& Law, 14, 189200. DOI: $10.1080 / 10683160701645181$

Hartwig, M., Granhag, P. A., \& Strömwall, L. A. (2007). Guilty and innocent suspects’ strategies during police interrogations. Psychology, Crime \& Law, 13, 213-227. DOI: $10.1080 / 10683160600750264$

Hartwig, M., Granhag, P. A., Strömwall, L. A., \& Doering, N. (2010). Impression and information management: On the strategic self-regulation of innocent and guilty suspects. The Open Criminology Journal, 3, 10-16.

DOI:10.2174/1874917801003010010

Harvey, A., Vrij, A., Hope, L., Leal, S., \& Mann, S. (2017). A stability bias effect among deceivers. Law and Human Behaviour, 41, 519-529. DOI: 10.1037/lhb0000258

Hope, L., Gabbert, F., \& Fisher, R. (2011). From laboratory to the street: Capturing witness memory using the Self-Administered Interview. Legal and criminological psychology, 16, 211-226. DOI: 10.1111/j.2044-8333.2011.02015.x 
Hope, L., Gabbert, F., Fisher, R. P., \& Jamieson, K. (2014). Protecting and enhancing Eyewitness Memory: The impact of an initial recall attempt on performance in an investigative interview. Applied Cognitive Psychology, 28, 304-313. DOI:10.1002/acp.2984

Kornell, N., \& Bjork, R. A. (2009). A stability bias in human memory: Overestimating remembering and underestimating learning. Journal of Experimental Psychology: General, 138, 449-468. DOI: 10.1037/a0017350

Lawson, M., \& London, K. (2015). Tell Me Everything You Discussed: Children's Memory for Dyadic Conversations after a 1-Week or a 3-Week Delay. Behavioral Sciences \& Law, 33, 429-445. DOI: 10.1002/bs1.2184

Lerner, M. J. (1980). The belief in a just world. New York, NY: Plenum.

Levy, B. J. \& Anderson, M. C. (2002). Inhibitory processes and the control of memory retrieval. Trends in Cognitive Sciences, 6, 299-305. DOI: 10.1016/S13646613(02)01923-X

London School of English. (2018). Level Scale. Retrieved from https://www.londonschool.com/level-scale/

MacLeod, M. D. (2002). Retrieval-induced forgetting in eyewitness memory: Forgetting as a consequence of remembering. Applied Cognitive Psychology, 16, 135-149. DOI: 10.1002/acp.782

Meissner, C. A., Surmon-Böhr, F., Oleszkiewicz, S. A., \& Alison, L. J. (2017). Developing an evidence-based perspective on interrogation: A review of the U.S. government's high-value detainee interrogation group research program. Psychology, Public Policy, and Law, 23, 438-457. DOI: 10.1037/law0000136

Memon, A., Meissner, C. A., \& Fraser, J. (2010). The Cognitive Interview: A meta-analytic review and study space analysis of the past 25 years. Psychology, Public Policy, \& Law, 16, 340-372. DOI: 10.1037/a0020518 
Milne, R. \& Bull, R. (1999). Investigative Interviewing: Psychology and Practice. Wiley, Chichester.

Nahari, G., \& Ben-Shakhar, G. (2011). Psychophysiological and behavioural measures for detecting concealed information: The role of memory for crime details. Psychophysiology, 48, 733-744. DOI: 10.1111/j.1469-8986.2010.01148.x

Nahari, G., Vrij, A., \& Fisher, R. P. (2014). Exploiting liars' verbal strategies by examining the verifiability of details. Legal and Criminological Psychology, 19, 227-239. DOI:10.1111/j.2044-8333.2012.02069.x

Oxburgh, G., Myklebust, T., \& Grant, T. (2010). The question of question types in police interviews: A review of the literature from a psychological and linguistic perspective. International Journal of Speech Language and the Law, 17, 45-66. DOI: 10.1558/ijsll.v17i1.45

Pansky, A, Koriat, A., \& Goldsmith, M. (2005). In N. Brewer \& K. D. Williams, Psychology and law: An empirical perspective (pp. 93-150). The Guilford Press, New York.

Pansky, A., \& Nemets, E. (2012). Enhancing quantity and accuracy of eyewitness memory via initial memory testing. Journal of Applied Research in Memory and Cognition, 1, 2-10. DOI: 10.1016/j.jarmac.2011.06.001

Pescod, L., Wilcock, L., Milne, R. (2013). Improving eyewitness memory in police call centre interviews. Policing: A Journal of Policy and Practice, 7, 299-306. DOI:10.1093/police/pat013

Shaw, D. J., Vrij, A., Leal, S., Mann, S., Hillman, J., Granhag, P. A., \& Fisher, R. P. (2015). Mimicry and investigative interviewing: Using deliberate mimicry to elicit information and cues to deceit. Journal of Investigative Psychology and Offender Profiling, 12, 217-230. DOI: 10.1002/jip.1438 
Shaw, J. S., Bjork, R. A., \& Handal, A. (1995). Retrieval-induced forgetting in an eyewitness paradigm. Psychonomic Bulletin \& Review, 2, 249-253. DOI: 10.3758/BF03210965

Schacter, D. L. (1999). The seven sins of memory: Insights from psychology and cognitive neuroscience. American Psychologist, 54, 182-203. DOI:10.1037/0003-066x.54.3.182

Strömwall, L. A., \& Granhag, P. A. (2003). How to detect deception? Arresting the beliefs of police officers, prosecutors and judges. Psychology, Crime \& Law, 9, 19-36. DOI: $10.1080 / 10683160308138$

Turtle, J. W., \& Yuille, J. C. (1994). Lost but not forgotten details: Repeated eyewitness recall leads to reminiscence but not hypermnesia. Journal of Applied Psychology, 79, 260-271. DOI: 10.1037/0021-9010.79.2.260

Vredeveldt, A., van Koppen, P. J., \& Granhag, P. A. (2014). The inconsistent suspect: A systematic review of different types of consistency in truth tellers and liars. In R. Bull (Ed.), Investigative Interviewing (pp. 183-207). New York, NY: Springer. DOI: 10.1007/978-1-4614-9642-7_10

Vrij, A. (2008). Detecting lies and deceit: Pitfalls and opportunities. Chichester, UK: John Wiley \& Sons.

Vrij, A. (2015). Verbal Lie Detection tools: Statement validity analysis, reality monitoring and scientific content analysis. In P. A. Granhag, A. Vrij \& B. Verschuere (Eds.), Detecting Deception Current Challenges and Cognitive Approaches (pp. 3-36). Chichester, UK: Wiley. DOI: 10.1002/9781118510001.ch1

Vrij, A., Fisher, R., \& Blank, H. (2017). A cognitive approach to lie detection: A metaanalysis. Legal and Criminological Psychology, 22, 1-21. DOI:10.1111/lcrp.12088

Vrij, A., \& Granhag, P. A. (2012). Eliciting cues to deception and truth: What matters are the questions asked. Journal of Applied Research in Memory and Cognition, 1, 110-117. DOI: $10.1016 /$ j.jarmac.2012.02.004 
Vrij, A., Hope, L., \& Fisher, R. P. (2014). Eliciting reliable information in investigative interviews. Policy Insights from Behavioral and Brain Sciences, 1, 129-136. DOI: $10.1177 / 2372732214548592$

Vrij, A., Leal, S., Granhag, P. A., Mann, S., Fisher, R. P., Hillman, J., \& Sperry, K. (2009). Outsmarting the liars: The benefit of asking unanticipated questions. Law and Human Behavior, 33, 159-166. DOI: 10.1007/s10979-008-9143-y

Vrij, A., Leal, S., Mann, S., Dalton, G. Jo, E., Shaboltas, A., Khaleeva, M., Granskaya, J., \& Houston, K. (2017). Using the Model Statement to elicit information and cues to deceit in interpreter-based interviews. Acta Psychologica, 177, 44-53. Doi: 10.1016/j.actpsy.2017.04.011

Walsh, D., \& Oxburgh, G. (2008). Investigative interviewing of suspects: Historical and contemporary developments in research. Forensic Update, 92, 41-45.

Warmelink, L., Vrij, A., Mann, S., \& Granhag, P. A. (2013). Spatial and temporal details in intentions: A cue to detecting deception. Applied Cognitive Psychology, 27, 101-106. DOI: $10.1002 /$ acp.v27.1

Wysman, L., Scoboria, A., Gawrylowicz, J., Memon, A. (2014). The cognitive interview buffers the effects of subsequent repeated questioning in the absence of negative feedback. Behavioral Sciences and Law, 32, 207-219. DOI: 10.1002/bs1.2115 
Table 1

Means, standard deviations and confidence intervals for responses to pre-interview and postinterview questionnaires

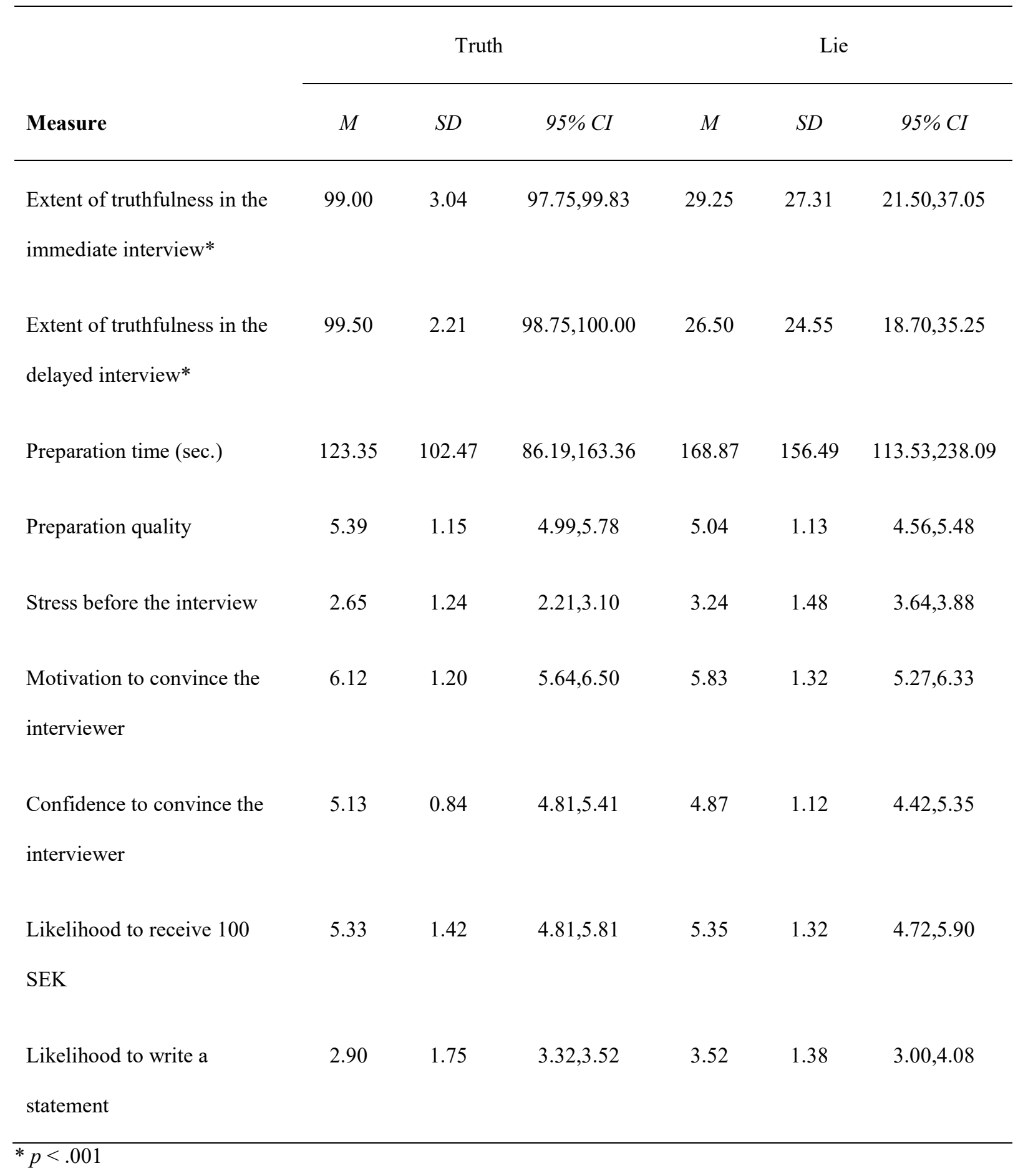


Table 2

Details in the delayed interview as a function of veracity and initial retrieval condition

\begin{tabular}{|c|c|c|c|c|c|c|c|c|c|}
\hline \multicolumn{5}{|c|}{ Truth } & \multicolumn{2}{|c|}{ Lie } & \multirow[b]{2}{*}{$F$} & \multirow[b]{2}{*}{$p$} & \multirow[b]{2}{*}{$d$} \\
\hline Detail & $M$ & $S D$ & $95 \% \mathrm{CI}$ & $M$ & $S D$ & $95 \% \mathrm{CI}$ & & & \\
\hline \multicolumn{10}{|c|}{ Comprehensive (Report everything) } \\
\hline Visual & 65.78 & 24.36 & $57.70,73.85$ & 29.00 & 10.67 & $21.34,36.66$ & 43.30 & $<.001$ & 1.96 \\
\hline Spatial & 33.11 & 15.36 & $28.15,38.07$ & 11.65 & 8.45 & $6.94,16.36$ & 39.09 & $<.001$ & 1.73 \\
\hline Temporal & 12.78 & 6.18 & $10.85,14.71$ & 4.05 & 2.74 & $2.22,5.88$ & 42.81 & $<.001$ & 1.83 \\
\hline Action & 37.22 & 14.57 & $32.78,41.67$ & 12.40 & 7.26 & $8.19,16.62$ & 65.17 & $<.001$ & 2.16 \\
\hline \multicolumn{10}{|c|}{ Selective (Questions) } \\
\hline Visual & 50.36 & 16.24 & $43.06,57.67$ & 29.60 & 15.74 & $21.94,37.26$ & 15.26 & $<.001$ & 1.30 \\
\hline Spatial & 20.82 & 10.17 & $16.33,25.30$ & 7.75 & 7.05 & $3.05,12.46$ & 16.03 & $<.001$ & 1.49 \\
\hline Temporal & 8.82 & 4.16 & $7.08,10.56$ & 2.25 & 2.57 & $0.42,4.08$ & 26.81 & $<.001$ & 1.90 \\
\hline Action & 22.00 & 7.63 & $17.98,26.02$ & 6.55 & 7.15 & $2.34,10.77$ & 27.92 & $<.001$ & 2.09 \\
\hline
\end{tabular}

Table 3

Details in the immediate interview as a function of veracity and initial retrieval condition

\begin{tabular}{|c|c|c|c|c|c|c|c|c|c|}
\hline \multicolumn{5}{|c|}{ Truth } & \multicolumn{2}{|c|}{ Lie } & \multirow[b]{2}{*}{$F$} & \multirow[b]{2}{*}{$p$} & \multirow[b]{2}{*}{$d$} \\
\hline Detail & $M$ & $S D$ & $95 \% \mathrm{CI}$ & $M$ & $S D$ & $95 \% \mathrm{CI}$ & & & \\
\hline \multicolumn{10}{|c|}{ Comprehensive (Report everything) } \\
\hline Visual & 67.72 & 29.81 & $58.03,77.41$ & 32.55 & 15.30 & $23.36,41.74$ & 27.51 & $<.001$ & 1.48 \\
\hline Spatial & 33.67 & 18.69 & $28.47,38.87$ & 13.50 & 9.30 & $8.57,18.43$ & 31.38 & $<.001$ & 1.37 \\
\hline Temporal & 16.00 & 8.01 & $13.79,18,22$ & 3.80 & 2.55 & $1,70,5.90$ & 63.18 & $<.001$ & 2.05 \\
\hline Action & 41.44 & 18.61 & $36,23,46,66$ & 12.95 & 7.45 & $8.01,17.89$ & 62.41 & $<.001$ & 2.01 \\
\hline \multicolumn{10}{|c|}{ Selective (Questions) } \\
\hline Visual & 60.68 & 15.10 & $51.92,69.45$ & 45.00 & 20.55 & $35.81,54.19$ & 6.05 & .016 & 0.87 \\
\hline Spatial & 17.45 & 6.28 & $12.75,22.16$ & 9.15 & 6.95 & $4.22,14.09$ & 5.88 & .018 & 1.25 \\
\hline Temporal & 5.00 & 4.08 & $2.99,7.01$ & 1.55 & 2.64 & $0.00,3.65$ & 5.59 & .021 & 1.00 \\
\hline Action & 12.91 & 8.61 & $8.20,17.62$ & 5.90 & 6.74 & $0.96,10.84$ & 4.18 & .044 & 0.91 \\
\hline
\end{tabular}


${ }^{\mathrm{i}}$ Data collection took place in Sweden. Part of the research team were non-Swedish speakers. Therefore, it was decided to conduct the interviews in English for convenience purposes, and then to transcribe and code the interviews. English proficiency level scale was adapted from the London School of English (2018). The scale consisted of six categories: i) Elementary ("I can say and understand a few things in English"); ii) Pre-intermediate ("I can communicate simply and understand in familiar situations, but only with some difficulty"); iii) Intermediate ("I can speak and understand reasonably well and can use basic tenses, but have problems with more complex grammar and vocabulary"); iv) Upper-intermediate ("I speak and understand well, but still make mistakes and fail to make myself understood occasionally"); v) Advanced (“I speak and understand very well, but sometimes have problems with familiar situations and vocabulary"); and vi) Very advanced ("I speak and understand English completely fluently"). Participants classified themselves as Intermediate 6.3\%, Upperintermediate $25 \%$, Advanced $37.5 \%$, and Very advanced $31.3 \%$, indicating that overall participants were fluent at speaking English. 